Article

\title{
Comprehensive Analysis of Neurotoxin-Induced Ablation of Dopaminergic Neurons in Zebrafish Larvae
}

\author{
Michael Kalyn ${ }^{1}$, Khang Hua ${ }^{1}{ }^{(}$, Suzita Mohd Noor $^{2}$, Chee Ern David Wong ${ }^{2}$ and Marc Ekker ${ }^{1, *}$ \\ 1 Department of Biology, Faculty of Science, University of Ottawa, ON K1N 6N5, Canada; \\ michael.t.kalyn@gmail.com (M.K.); khanghua88@gmail.com (K.H.) \\ 2 Department of Biomedical Science, Faculty of Medicine, University of Malaya, Kuala Lumpur 50603, \\ Malaysia; suzita@um.edu.my (S.M.N.); davidwce89@gmail.com (C.E.D.W.) \\ * Correspondence: mekker@uottawa.ca; Tel.: +1-613-562-5800 (ext. 2605)
}

Received: 22 November 2019; Accepted: 25 December 2019; Published: 28 December 2019

check for updates

\begin{abstract}
Neurotoxin exposure of zebrafish larvae has been used to mimic a Parkinson's disease (PD) phenotype and to facilitate high-throughput drug screening. However, the vulnerability of zebrafish to various neurotoxins was shown to be variable. Here, we provide a direct comparison of ablative effectiveness in order to identify the optimal neurotoxin-mediated dopaminergic (DAnergic) neuronal death in larval zebrafish. Transgenic zebrafish, $\operatorname{Tg}($ dat:eGFP), were exposed to different concentrations of the neurotoxins MPTP, $\mathrm{MPP}^{+}$, paraquat, 6-OHDA, and rotenone for four days, starting at three days post-fertilization. The $\mathrm{LC}_{50}$ of each respective neurotoxin concentration was determined. Confocal live imaging on $\mathrm{Tg}\left(\right.$ dat:eGFP) showed that MPTP, $\mathrm{MPP}^{+}$, and rotenone caused comparable DAnergic cell loss in the ventral diencephalon (vDC) region while, paraquat and 6-OHDA caused fewer losses of DAnergic cells. These results were further supported by respective gene expression analyses of dat, th, and $p 53$. Importantly, the loss of DAnergic cells from exposure to $\mathrm{MPTP}, \mathrm{MPP}^{+}$, and rotenone impacted larval locomotor function. MPTP induced the largest motor deficit, but this was accompanied by the most severe morphological impairment. We conclude that, of the tested neurotoxins, $\mathrm{MPP}^{+}$recapitulates a substantial degree of DAnergic ablation and slight locomotor perturbations without systemic defects indicative of a Parkinsonian phenotype.
\end{abstract}

Keywords: Parkinson's disease; neurotoxins; dopaminergic neurons; ventral diencephalon; locomotor; zebrafish

\section{Introduction}

Parkinson's Disease (PD) is a progressive and debilitating neurodegenerative disease in which clinical hallmarks comprise motor and cognitive impairments. Pathologically, motor symptoms in humans arise due to the progressive and irreversible loss of dopaminergic (DAnergic) neurons within the substantia nigra [1]. Although the etiology of PD remains ambiguous, it is likely due to the cumulative result of genetic and environmental insult. Familial PD has been linked to mutations in genes, however, this can only explain $15-30 \%$ of cases while the majority of cases are sporadic [2]. It is believed that exposure to environmental toxins is widely associated with idiopathic PD [3].

Animal models contribute to our knowledge of PD progression and help explore possible therapeutics. Chemo-ablative models using neurotoxic compounds such as 1-methyl-4-phenyl-1,2,3, 6-tetrahydropyridine (MPTP), 1-methyl-4-phenyl-pyridinium $\left(\mathrm{MPP}^{+}\right)$, 6-hydroxydopamine (6-OHDA), rotenone, and paraquat have been used to study the molecular mechanisms of DAnergic neurodegeneration in mammals [4-8]. The zebrafish (Danio rerio) has proven to be a robust 
in vivo vertebrate animal model for the studies of various neurodegenerative diseases $[9,10]$ and high-throughput drug screening [11] due to their large clutch size and transparent ex utero embryogenesis. With $\sim 87 \%$ of their genome similar to humans, zebrafish also display a variety of conserved molecular and pathological pathways [12]. In particular, a proportion of the DAnergic system in zebrafish (primarily in the ventral diencephalic region) is postulated to be functionally homologous to that of the nigrostriatal pathway in mammals $[13,14]$. Dopaminergic projections in zebrafish are fully formed by 3-4 days post-fertilization (dpf) [12,15] compared to E12.5 observed in mice [16], E20 in rats [17], and by embryonic day 73 in macaques [18]. The rapid neurodevelopment and optical transparency throughout embryogenesis in zebrafish allow for facilitated study of DAnergic-related diseases such as PD.

MPTP is the most widely used neurotoxin to induce DAnergic neuronal loss and PD-associated locomotor phenotypes in many animal models $[4,19,20]$. MPTP is lipophilic and it is metabolized by astrocytes (glia) into its active toxic form, $\mathrm{MPP}^{+}$, by monoamine oxidase $\mathrm{B}$ (MAO-B). $\mathrm{MPP}^{+}$enters DAnergic neurons through the dopamine transporter (dat) where it can act on complex I of the electron transport chain (ETC), resulting in the inhibition of ATP synthesis, mitochondrial respiration, and in the promotion of superoxide radical production $[7,20]$.

Paraquat is the most predominantly used commercial herbicide [21,22]. Recent epidemiological studies have outlined the increased risk of developing PD following extensive exposure to paraquat [23]. This divalent cation undergoes redox cycling and its presence results in enhanced oxidative-stress within DAnergic mitochondria [24]. However, exposure to paraquat has been shown to yield inconsistent reports in the literature. This is particularly evident in zebrafish studies, where some have outlined a severe neurodegenerative impact of paraquat on dopamine and serotonin protein levels $[25,26]$, while others observed no obvious phenotypes [10]. This variable effect extends to behavioral symptoms following treatment, where some groups observed significant motor impairment [27], while others report no fluctuations in any swimming activity parameter [10]. These results may be the consequence of varying treatment regimens. Paraquat-induced Parkinsonian-related phenotypes in vivo warrant further investigation.

6-OHDA is a synthetically hydroxylated dopamine compound that is taken up into catecholaminergic neurons through dopamine or norepinephrine transporters [28,29]. 6-OHDA exposure is commonly co-administered with a norepinephrine transporter inhibitor to increase the specificity of neurotoxicity to DAnergic neurons [30,31]. Although 6-OHDA has been shown to be effective in inducing DAnergic neuronal loss in a wide variety of mammals from mice, cats, dogs, monkeys, and rats [5], few studies have shown the sensitivity of zebrafish to 6-OHDA.

Likewise, rotenone is commonly used as an industrial insecticide and as piscicide, a compound used to eradicate fish [32]. Rotenone's hydrophobic nature allows for the easy penetrance of astrocyte and neuronal cellular membranes [33,34]. The mechanism of action of rotenone is similar to MPTP, through the impairment of complex I of the ETC. Additionally, through nuclear translocation, rotenone leads to the activation of NF- $\mathrm{kB}$ and the subsequent DNA fragmentation to result in cellular damage [35]. The toxic nature of rotenone to fish makes it difficult to determine an optimal dose that results in efficient DAnergic ablation with low mortality. Rotenone exposure studies in zebrafish have yielded conflicting results $[10,36]$

To date, the susceptibility of zebrafish to neurotoxic drugs remains contradictory. This may be due to varying concentrations, duration of exposure, and initial time of treatment which typically occurs at $24 \mathrm{~h}$ post-fertilization (hpf), before the full DAnergic neuronal system and blood-brain barrier (BBB) have developed [15]. In addition, behavioral assays and methods of determining DAnergic neuronal loss vary greatly between studies. Most studies primarily utilize TH as a marker for detecting DAnergic cells in either in situ hybridization or whole mount immunostaining approaches. The use of a transgenic model, $\operatorname{Tg}($ dat:eGFP) [37] that expresses enhanced green fluorescent protein (eGFP) under the control of the dopamine transporter (dat) cis-regulatory element in zebrafish, allows for live visualization of DAnergic neurons. In this study, we provide a comprehensive comparison of 
PD-associated neurotoxins and determine the optimal concentration required to induce maximal decrease of DAnergic neurons along with PD-like locomotor phenotypes.

\section{Materials and Methods}

\subsection{Zebrafish Care and Husbandry}

Transgenic zebrafish of the $\operatorname{Tg}($ dat:eGFP) line [37] were used in this study. Zebrafish were maintained at $28.5^{\circ} \mathrm{C}$ under a 14 -h light/10-h dark cycle. Embryos were collected by natural spawning and raised in E3 embryo media ( $13 \mathrm{mM} \mathrm{NaCl}, 0.5 \mathrm{mM} \mathrm{KCL}, 0.02 \mathrm{mM} \mathrm{Na}_{2} \mathrm{HPO}_{4}, 0.04 \mathrm{mM} \mathrm{KH}_{2} \mathrm{PO}_{4}$, $1.3 \mathrm{mM} \mathrm{CaCl}_{2}, 1.0 \mathrm{mM} \mathrm{MgSO}_{4}$, and $4.2 \mathrm{mM} \mathrm{NaHCO}_{3}$ ). Embryos were screened using fluorescence microscopy and $\mathrm{eGFP}^{+}$larvae were sorted accordingly. We expressed the embryonic stages in days post-fertilization (dpf). The University of Ottawa Animal Care Committee approved all animal care procedures, which were conducted under the Animal Care and Veterinary Service guidance in accordance with the recommendations of the Canadian Council for Animal Care following ethical code BL-2081.

\subsection{Environmental Toxin Preparation and Exposure}

At $3 \mathrm{dpf}, 20$ larvae were sorted and placed into each well of a 6-well plate in a solution volume of 3 $\mathrm{mL}$. De-chorionated larvae were treated at $3 \mathrm{dpf}$ until $7 \mathrm{dpf}$. Room temperature $\left(\sim 23^{\circ} \mathrm{C}\right)$ was chosen for exposures due to an increase of rotenone-associated neurotoxicity observed at $28.5^{\circ} \mathrm{C}$ [38] and to ensure all treatment groups are exposed to the same conditions. Five different concentrations were chosen to determine an accurate sub-lethal dosage. The exposure gradient followed an increasing half log series. Solutions were changed daily and replaced with freshly prepared ones. Toxins were discarded in accordance to current safety protocols. All larvae were co-treated with $0.2 \mathrm{M}$ phenylthiourea (PTU), a pigmentation inhibitor, to facilitate confocal live imaging. Previous studies have shown that PTU does not impair th or dat expression throughout embryonic and larval neurodevelopment [13].

1-methyl-4-phenyl-1,2,3,6-tetrahydropyridine hydrochloride (MPTP; $\mathrm{C}_{12} \mathrm{H}_{15} \mathrm{~N} \cdot \mathrm{HCl}$, Product: M0896, CAS: 23007-85-4, Sigma, Oakville, ON, Canada) was reconstituted in distilled water to a stock concentration of $500 \mathrm{mM}$. MPTP was further diluted to the working concentrations of $0.25 \mathrm{mM}, 0.5 \mathrm{mM}$, $1.0 \mathrm{mM}, 1.5 \mathrm{mM}$, and $2.5 \mathrm{mM}$. MPP ${ }^{+}$iodide ( $\geq 98 \%, \mathrm{C}_{12} \mathrm{H}_{12} \mathrm{IN}$, Product: D048, CAS: 36913-39-0, Sigma) was re-constituted in distilled water to a stock concentration of $4.86 \mathrm{mM}$. MPP ${ }^{+}$was further diluted to the working concentrations of $0.025 \mathrm{mM}, 0.05 \mathrm{mM}, 0.075 \mathrm{mM}, 0.1 \mathrm{mM}$, and $0.5 \mathrm{mM}$. Methyl viologen dichloride hydrate (Paraquat; $\geq 98 \%, \mathrm{C}_{12} \mathrm{H}_{14} \mathrm{Cl}_{2} \mathrm{~N}_{2} \cdot x \mathrm{x}_{2} \mathrm{O}$, Product: 856177, CAS: 75265-73-0, Sigma) was reconstituted with sterile distilled water at a concentration of $100 \mathrm{mM}$, then diluted into $25 \mathrm{mM}$, $10 \mathrm{mM}, 5 \mathrm{mM}, 3 \mathrm{mM}$, and $1 \mathrm{mM}$ working dosages. 6-Hydroxydopamine hydro-chloride (6-OHDA; $\geq 97 \%$, $(\mathrm{HO})_{3} \mathrm{C}_{6} \mathrm{H}_{2} \mathrm{CH}_{2} \mathrm{NH}_{2} \cdot \mathrm{HCL}$, Product: H4381, CAS: 28094-15-7, Sigma) was dissolved in and co-administered with $1 \%$ ascorbic acid to prevent precipitation and preserve molecular stability at a concentration of $100 \mu \mathrm{m}$. The solution was further diluted to the working concentrations of $30 \mu \mathrm{M}$, $10 \mu \mathrm{M}, 3 \mu \mathrm{M}$, and $1 \mu \mathrm{M}$. Controls for 6-OHDA were exposed to a $0.01 \%$ ascorbic acid solution. Rotenone ( $\geq 95 \%, \mathrm{C}_{23} \mathrm{H}_{22} \mathrm{O}_{6}$, Product: R8875, CAS: 83-79-4, Sigma) was prepared in $100 \%$ dimethyl sulfoxide DMSO at a concentration of $100 \mathrm{mM}$, then serially diluted up to 1,000,000-fold in $10 \%$ water-diluted DMSO to working concentrations of $5 \mathrm{nM}, 10 \mathrm{nM}, 25 \mathrm{nM}, 50 \mathrm{nM}$, and $100 \mathrm{nM}$. Rotenone controls were exposed to a $0.01 \%$ DMSO solution. All treatments were conducted in the dark as MPP ${ }^{+}$, 6-OHDA, and rotenone are photosensitive.

\subsection{Live Confocal Imaging}

At $7 \mathrm{dpf}$, treated zebrafish larvae were transferred from their respective exposure media to fish water, anaesthetized with $3 \times$ tricaine, and live-mounted dorsal side up on slides using a $1 \%$ low-melting point agarose solution. Larvae were continuously re-hydrated while mounted using system water to ensure survival. Imaging was conducted using the Nikon A1 confocal microscope with a $25 \times$ water 
immersion objective. Larvae were scanned using the laser at a wavelength of $488 \mathrm{~nm}$ to excite eGFP. Images were obtained in a 2-3 $\mu \mathrm{m}$ interval Z-stack that was processed and compiled to produce a three-dimensional image. The total cell numbers for clusters 8, 12, and 13 were determined in 3-D to avoid repeated counts of the same cell and by three independent researchers in a blinded fashion to remove bias. Maximum intensity projection images used for the study were produced using the NIS-Elements software (Nikon, Mississauga, ON, Canada).

\subsection{RNA Isolation and $q R T-P C R$}

RNA was extracted from five pools of 10 pestle-homogenized whole larvae using TRIzol (InVitrogen, ThermoFisher, Waltham, MA, USA). Extractions were done according to the manufacturer's protocol. RNA integrity and purity was determined using gel electrophoresis and the NanoDrop 1000 Spectrophotometer (ThermoFisher, Waltham, MA, USA). Samples with clear 18S, 28 S bands and an absorbance ratio of 1.8-2.1 were used for cDNA synthesis. RNA was reverse-transcribed using the iScript $^{\mathrm{TM}}$ cDNA Synthesis Kit (Life Science Research, Bio-Rad, St Laurent, Qc, Canada) in accordance with the manufacturer's protocol. qRT-PCR reactions were composed of $5 \mu \mathrm{L}$ SsoFast ${ }^{\mathrm{TM}}$ EvaGreen $^{\circledR}$ Supermix (Bio-Rad), $0.4 \mu \mathrm{L}$ reverse primer, $0.4 \mu \mathrm{L}$ forward primer, $0.2 \mu \mathrm{L}$ nuclease-free water and $4 \mu \mathrm{L}$ cDNA. Reactions were done in triplicates using the Bio-Rad CFX96 instrument. Normalized quantification of the number of $t h 1$, dat, and $p 53$ transcripts was achieved through the comparative Cq method using three reference genes; tyrosine 3-monooxygenase/tryptophan 5-monooxygenase activation protein, zeta polypeptide (ywhaz), ribosomal protein 113a (rpl13a), and elongation factor 1 alpha (ef1a). Oligonucleotide primers are listed in Table 1.

Table 1. List of primers designed for qRT-PCR.

\begin{tabular}{cccc}
\hline Primer & Forward Sequence $\left(\mathbf{5}^{\prime} \mathbf{-} \mathbf{3}^{\prime}\right)$ & Reverse Sequence $\left(\mathbf{5}^{\prime} \mathbf{- \mathbf { 3 } ^ { \prime } )}\right.$ & Reference \\
\hline$d a t$ & AGACATCTGGGAAGGTGGTG & ACCTGAGCATCATACAGGCG & {$[39]$} \\
$t h 1$ & GACGGAAGATGATCGGAGACA & CCGCCATGTTCCGATTTCT & {$[40]$} \\
$p 53$ & ATATCCTGGCGAACATTTGG & ACGTCCACCACCACCATTTGAAC & \\
$y w h a z$ & TCTGCAATGATGTGTTGGAGC & TCAATGGTTGCTTTCTTGTCGTC & \\
$r p l 13 a$ & TCTGGAGGACTGTAAGAGGTATGC & AGACGCACAATCTTGAGAGCAG & {$[41]$} \\
$e f 1 a$ & CTGGAGGCCAGCTCAAACAT & ATCAAGAAGAGTAGTACCGCTAGCATTAC & \\
\hline
\end{tabular}

\subsection{Swimming Activity}

Following neurotoxin treatment, $7 \mathrm{dpf}$ larval zebrafish from each treatment group (6-OHDA, Paraquat, Rotenone, $\mathrm{MPP}^{+}$, and MPTP) were removed from their exposure media and monitored for their swimming activity. Individual larvae were transferred to E3 embryo media, placed in a 6-well plate, and allowed to acclimate in ambient light for $15 \mathrm{~min}$ prior to recording. The activity was recorded using the Zebralab software and the Zebrabox tracking system (ViewPoint Life Science, Lyon, France). The tracking system consists of infrared illumination, LED lights, and a mounted camera for swimming recording under dark and light conditions. The parameters of larval swimming activity were total distance travelled and the average velocity for $5 \mathrm{~min}$ trials. Sample sizes of 18-25 were chosen to delineate the effects of each compound from natural variability in locomotion exhibited by larvae. Touch stimuli response was conducted by gently touching the posterior portion of the tail of 20-30 larvae from each respective group and was qualitatively assessed as normal or reduced (slow response or absence of response).

\subsection{Statistical Analysis}

Statistical analysis was done using the software GraphPad Prism v.7 (San Diego, CA, USA). Swimming activity was evaluated on sample sizes ranging from 18-25 individuals, $\mathrm{eGFP}^{+}$cell counts were quantified from 10-15 zebrafish, and gene expression data were collected from three pools of 10 embryos. Data are shown as the mean \pm the standard error of the mean. The total distance and 
average velocity were analyzed using a one-way ANOVA followed by Dunnett's multiple comparison test. vDC cell loss was analyzed using a two-way ANOVA followed by Tukey's multiple comparison test. Gene expression data were calculated using a multiple t-test comparison with significance determined using the Holm-Sidak method. Statistical significance was determined when $p$-value $<0.05$ and was indicated as ${ }^{*} p<0.05,{ }^{* *} p<0.01,{ }^{* * *} p<0.001$.

\section{Results}

Given the ambiguity in alternative neurotoxin-mediated studies, the current study aimed at providing direct comparisons on the in vivo effects of PD-inducing neurotoxins to identify the optimal candidate for DAnergic neuron ablation and motor phenotypes. All treatments were conducted starting at $3 \mathrm{dpf}$ to prevent the inhibition of neurogenesis and because there is, at this time, near complete DAnergic differentiation and BBB development [12]. The varying concentrations used were to determine the optimal dose for each compound that would result in greater than $50 \%$ survival and could be used in subsequent analyses. Following the establishment of each $\mathrm{LC}_{50}$ concentration, DAnergic neuronal death was quantified through in vivo imaging of $\mathrm{eGFP}^{+}$cells in various clusters of the vDC. These regions were chosen due to the proposed homology of this area to the nigrostriatal pathway depicted in higher vertebrate species $[13,14]$. In parallel, larval zebrafish exposed to each compound were examined for locomotor perturbances. Conducted under the same exposure regimen, these data will identify the most efficient of the neurotoxins to induce DAnergic ablation and motor impairment with any potential off target morphological malformations. This will serve as a platform for high-throughput pharmacological screening aimed at alleviating cellular, locomotor or morphological insults.

\subsection{Effective $L_{50}$ Dose for PD Phenotypic Induction (Survival Curve/Median Lethal Concentration)}

Following an MPTP exposure $(0.25,0.5,1.0,1.5 \mathrm{mM}$, and $2.5 \mathrm{mM})$, the identified $\mathrm{LC}_{50}$ dose to carry out further DAnergic analyses was $0.25 \mathrm{mM}$ (Figure 1A). Concentrations of $2.5 \mathrm{mM}$ and $1.5 \mathrm{mM}$ resulted in complete mortality at 3-days post treatment (dpt) and $4 \mathrm{dpt}$ respectively. In contrast, concentrations of $1.0 \mathrm{mM}$ and $1.5 \mathrm{mM}$ resulted in severe malformations and were shown to be completely lethal at $5 \mathrm{dpt}$. The selected concentration of $0.25 \mathrm{mM}$ resulted in $>50 \%$ survival, however, it is noted the mortality increased 2.5-fold from $4 \mathrm{dpt}$ to $5 \mathrm{dpt}$.

Upon exposure to $\mathrm{MPP}^{+}$, larvae treated with concentrations exceeding $0.05 \mathrm{mM}$ showed $100 \%$ lethality by $7 \mathrm{dpf}$, whereas larvae treated with $0.05 \mathrm{mM}$ displayed over $50 \%$ survival (Figure 1B) without severe morphological defects (Figure 2).

Table 2. Summary of $\mathrm{LC}_{50}$ neurotoxic effects of $\mathrm{MPTP}, \mathrm{MPP}^{+}$, paraquat, 6-OHDA, and rotenone.

\begin{tabular}{|c|c|c|c|c|c|}
\hline Drug & $\begin{array}{c}\mathrm{LC}_{50} \\
\text { Concentration }\end{array}$ & Locomotion & $\begin{array}{c}\text { Global vDC } \\
\text { DAnergic Loss (\%) }\end{array}$ & $\begin{array}{l}\text { Morphological } \\
\text { Defects }\end{array}$ & Other Effects \\
\hline МРТP & $0.25 \mathrm{mM}$ & Severe & $39 \%$ & $\begin{array}{l}\text { Cardiac and tail } \\
\text { curvature }(9 / 20)\end{array}$ & Unresponsive to touch \\
\hline $\mathrm{MPP}^{+}$ & $0.05 \mathrm{mM}$ & Moderate & $35 \%$ & None of significance & Unresponsive to touch \\
\hline Paraquat & $1 \mathrm{mM}$ & None & $16 \%$ & $\begin{array}{c}\text { Stunted development } \\
(3 / 20)\end{array}$ & None of significance \\
\hline 6-OHDA & $1 \mu \mathrm{M}$ & None & $18 \%$ & Cardiac defect $(2 / 20)$ & None of significance \\
\hline Rotenone & $50 \mathrm{nM}$ & Moderate & $36 \%$ & Cardiac defect $(4 / 20)$ & None of significance \\
\hline
\end{tabular}


A

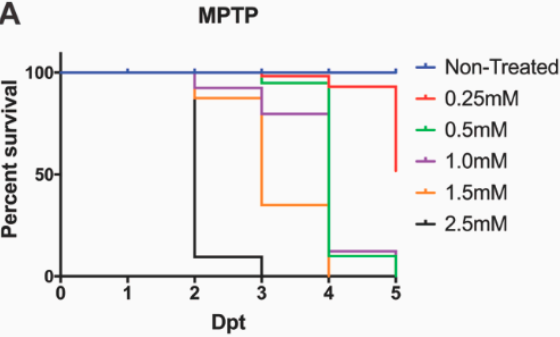

C
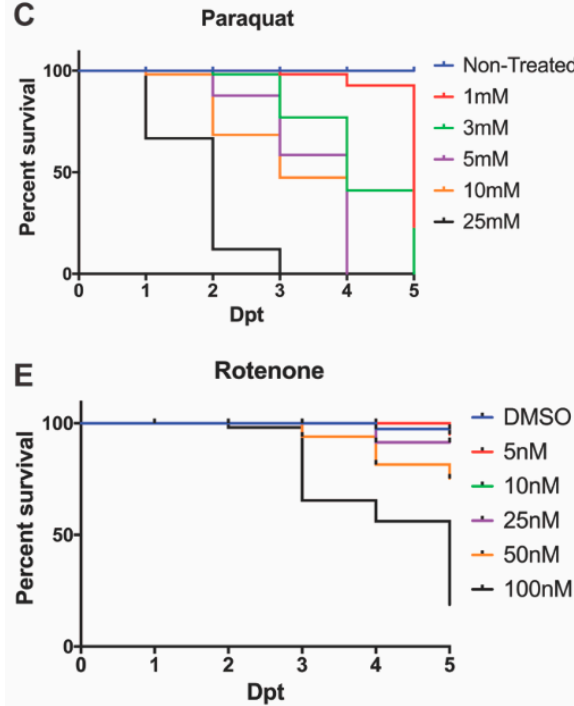

B

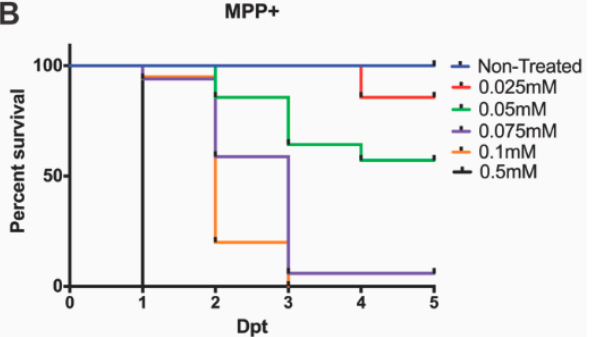

D

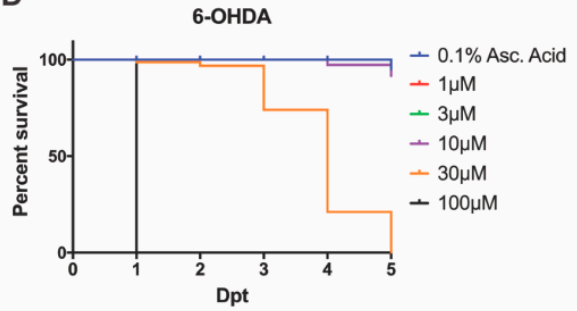

Figure 1. Zebrafish larvae survival following neurotoxin exposure. $3 \mathrm{dpf}$ embryos were exposed to varying concentrations of (A) MPTP, (B) $\mathrm{MPP}^{+},(\mathbf{C})$ paraquat, (D) 6-OHDA, and (E) rotenone to determine the $\mathrm{LC}_{50}$ or sub-lethal dose. Lethality was quantified every $24 \mathrm{hpt}$ until the zebrafish reached $7 \mathrm{dpf}$.

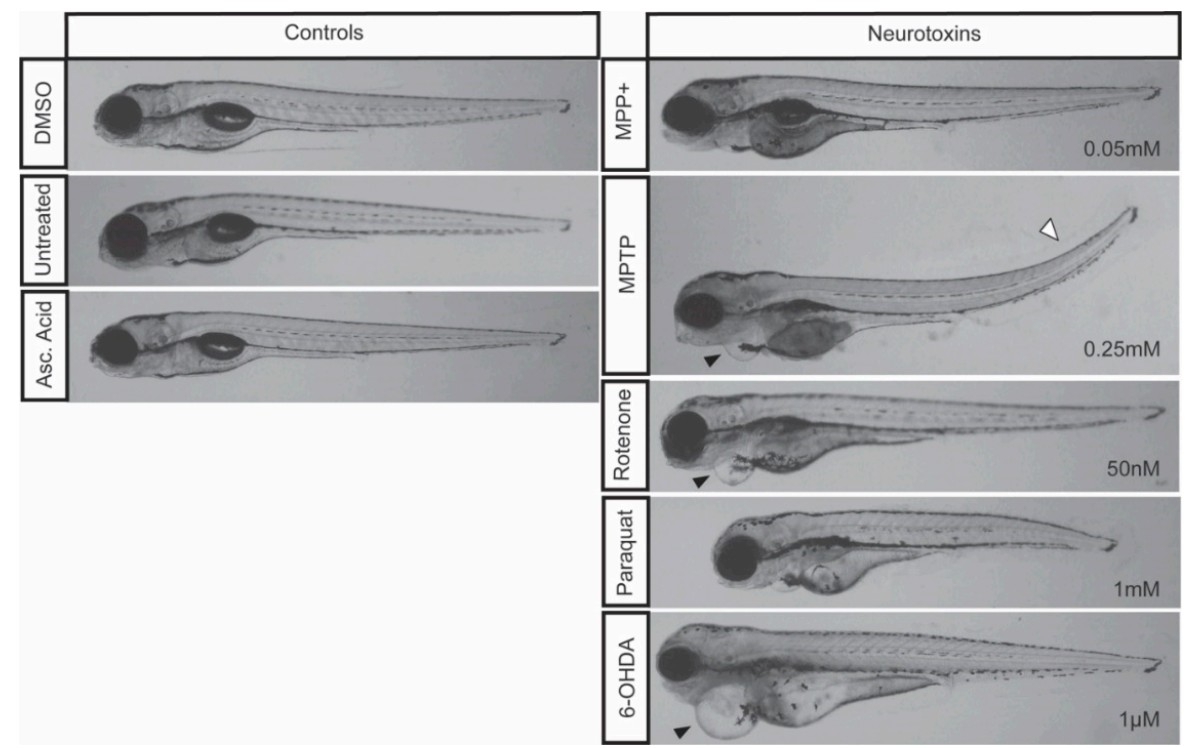

Figure 2. Zebrafish morphology following neurotoxic exposures. Larvae were exposed to $0.05 \mathrm{mM}$ $\mathrm{MPP}^{+}, 0.25 \mathrm{mM}$ MPTP, $50 \mathrm{nM}$ rotenone, $1 \mathrm{mM}$ paraquat, and $1 \mu \mathrm{M} 6-\mathrm{OHDA}$ starting at $3 \mathrm{dpf}$ and imaged at $7 \mathrm{dpf}$. Control larvae were exposed to $0.1 \%$ DMSO, $0.1 \%$ ascorbic acid, or left untreated. Cardiac defects are depicted by a black arrowhead and a tail curvature is depicted by a white arrowhead. Refer to Table 2 for the frequency of each morphological malformation. 
The herbicide paraquat was analyzed for its cytotoxic effects on DAnergic neurons due to its properties as an oxidizing agent. Exposure to $25 \mathrm{mM}$ paraquat was shown to be lethal by $3 \mathrm{dpt}$, whereas, at $5 \mathrm{mM}$ and $10 \mathrm{mM} \mathrm{100 \%} \mathrm{lethality} \mathrm{was} \mathrm{observed} \mathrm{by} 4 \mathrm{dpt}$. Consequently, a concentration of $1 \mathrm{mM}$ was used to examine a DAnergic loss phenotypic. This concentration contrasted with a previous report by [10], where exposure to $3 \mathrm{mM}$ for two days resulted in complete mortality by $5 \mathrm{dpt}$ (Figure 1C).

6-OHDA was administered at concentrations that ranged from $1 \mu \mathrm{M}$ to $100 \mu \mathrm{M}$. A concentration of $100 \mu \mathrm{M}$ resulted in $100 \%$ mortality at $1 \mathrm{dpt}$, whereas $30 \mu \mathrm{M}$ was shown to be completely lethal by $5 \mathrm{dpt}$. Larvae exposed to concentrations of $1 \mu \mathrm{M}, 3 \mu \mathrm{M}$, and $10 \mu \mathrm{M}$ displayed $>75 \%$ survival (Figure 1D).

Previous studies have utilized concentrations of rotenone ranging from $10 \mathrm{nM}$ to $1 \mathrm{uM}$ under various treatment regimens [36,38,42]. Here, we tested a range from $5 \mathrm{nM}$ to $100 \mathrm{nM}$ from $3 \mathrm{dpf}$ to $7 \mathrm{dpf}$. The $\mathrm{LC}_{50}$ dose was observed to be $50 \mathrm{nM}$ (Figure 1E). All further experimentation with rotenone was carried out using this dose.

\subsection{DAnergic Neuronal Loss in the Ventral Diencephalon (vDC)}

To determine the degree of DAnergic neuronal decrease in the $\mathrm{VDC}$, we treated $3 \mathrm{dpf}$ larvae for four days with MPTP, $\mathrm{MPP}^{+}, 6-\mathrm{OHDA}$, and paraquat at their respective $\mathrm{LC}_{50}$ concentrations. Following exposure to $0.25 \mathrm{mM}$ MPTP, larvae displayed a $39 \%$ decrease in the total number of eGFP positive neurons in clusters 8,12 , and 13 of the vDC. We observed a $56 \%$ and $35 \%$ decrease in clusters 8 and 13, respectively, in MPTP-treated animals compared to controls, while there was no significant difference in cluster 12 (Figure 3B-D). Larvae exposed to $0.05 \mathrm{mM} \mathrm{MPP}^{+}$exhibited similar decreases in clusters 8 and 13 with $41 \%$ and $35 \%$ reduction, respectively, while cluster 12 remained unaffected. DAnergic cells expressing eGFP were shown to decrease by $36 \%$ globally between these vDC clusters (Figure 3E-G).

In larvae treated with $1 \mathrm{uM} 6-\mathrm{OHDA}$, there was a 19\% decrease in the number of DAnergic neurons within the vDC. Interestingly, when looking at the changes within individual clusters, decreases did not reach statistical significance although there was a clear trend (Figure $3 \mathrm{H}-\mathrm{J}$ ).

Exposure of fish to paraquat resulted in a 18\% decrease in global ventral diencephalic DAnergic neurons, however, changes in individual clusters did not reach statistical significance (Figure $3 \mathrm{~K}-\mathrm{M}$ ).

Exposure to $50 \mathrm{nM}$ rotenone was shown to significantly impact all three DAnergic clusters. Reductions of $49 \%, 35 \%$, and $33 \%$ were observed following rotenone treatment in clusters 8,12 , and 13 , respectively. The combined DAnergic loss cumulated to $38 \%$ within the vDC (Figure $3 \mathrm{~N}-\mathrm{P}$ ). 
A
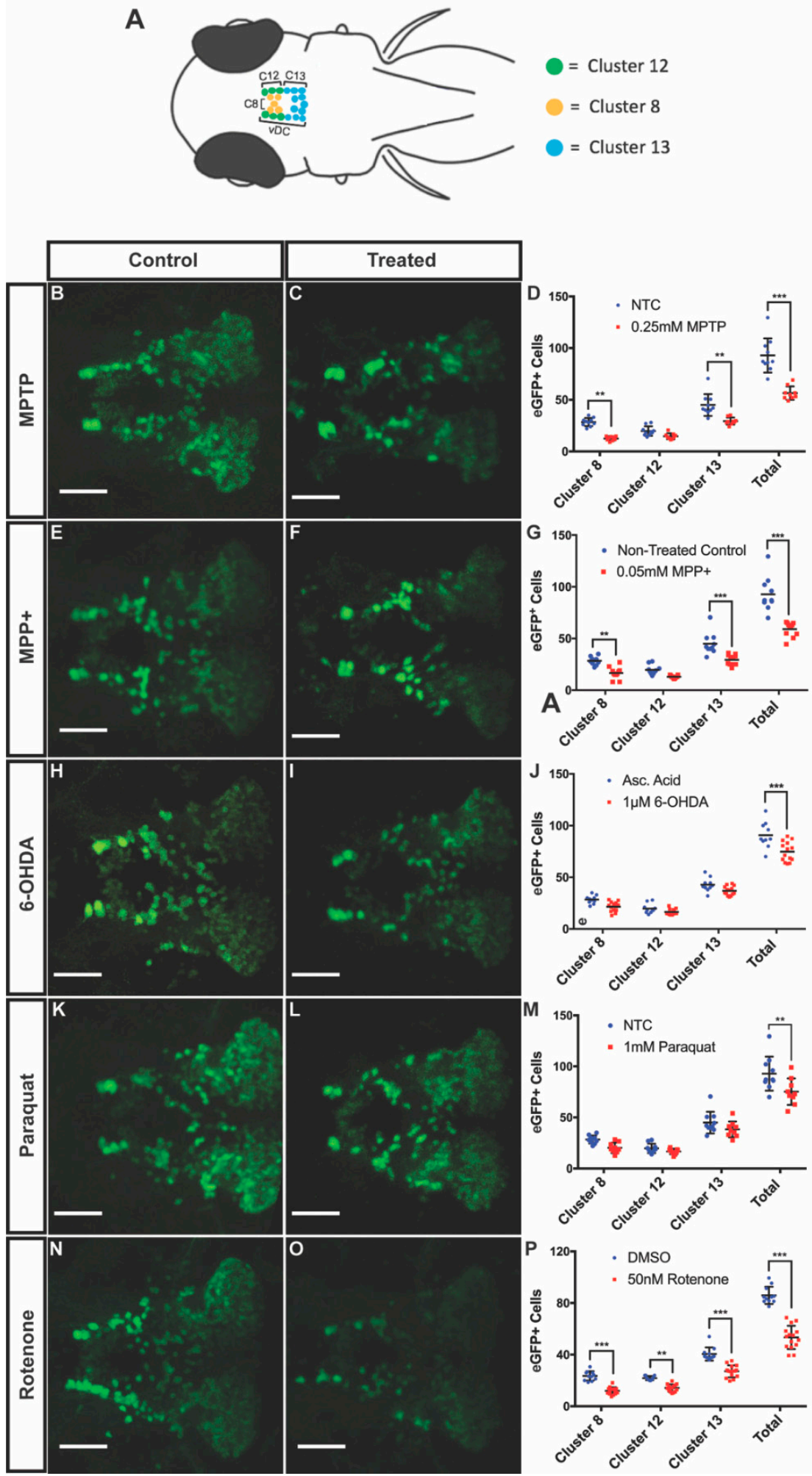

Figure 3. Effects of neurotoxins on ventral diencephalic (vDC) DAnergic clusters of $7 \mathrm{dpf} \operatorname{Tg}($ dat:eGFP) zebrafish. (A) Schematic representation of eGFP neuronal clusters 8, 12, and 13 within the vDC. Cluster 8 in yellow, cluster 12 in green, and cluster 13 in blue. Dorsal view with anterior to the left. (B-P) Quantification eGFP ${ }^{+}$cells within the vDC through confocal fluorescent live imaging following exposure to $0.25 \mathrm{mM}$ MPTP, $0.05 \mathrm{mM} \mathrm{MPP}^{+}, 1 \mathrm{uM}$ 6-OHDA, $1 \mathrm{mM}$ paraquat, and $50 \mathrm{nM}$ rotenone $(n=9-15)$. All images were acquired using a maximum projection of $2 \mu \mathrm{m}$ z-stacks, scale bar $=100 \mu \mathrm{m}$. Bars represent the Mean \pm the SEM. ${ }^{*}(p<0.05),{ }^{* *}(p<0.01),{ }^{* * *}(p<0.001)$. 


\subsection{Gene Expression}

We analyzed expression of genes such as tyrosine hydroxylase 1 (gene: th1; protein: $\mathrm{TH}$ ) and dopamine transporter (gene: dat; protein: DAT) to see if they correlated with the observed decreases in DAnergic cell numbers. In addition, we investigated whether neurotoxin exposure would trigger neuronal apoptosis through the $p 53$ pathway by looking at its mRNA expression. MPTP-treated larvae exhibited a $60 \%$ and $31 \%$ in th1 and dat expression relative to the non-treated control, whereas, p53 expression was shown to increase by $35 \%$ (Figure 4A). Following $\mathrm{MPP}^{+}$exposure, there were $36 \%$ and $55 \%$ decreases in the expression of th1 and dat respectively in treated compared to control fish. There was also a 39\% increase in $p 53$ expression in $\mathrm{MPP}^{+}$treated fish (Figure 4B). Paraquat exposure resulted in a $41 \%$ and $37 \%$ decrease in th1 and dat expression respectively. However, there was no change in the expression of $p 53$ (Figure 4C). 6-OHDA exposure resulted in a 55\% decrease only in th1 while dat and $p 53$ expression was unaffected (Figure 4D). Finally, rotenone was shown to significantly impact th1 expression resulting in a $41 \%$ reduction, whereas the expression of dat and p53 were observed to be slightly upregulated, although changes did not reach statistical significance (Figure 4E).

A

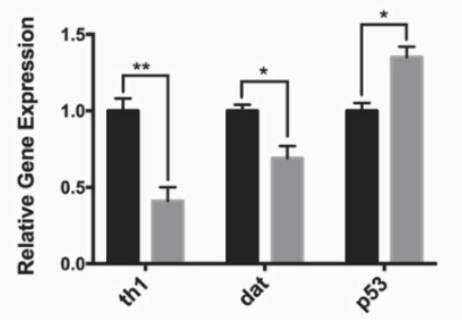

C

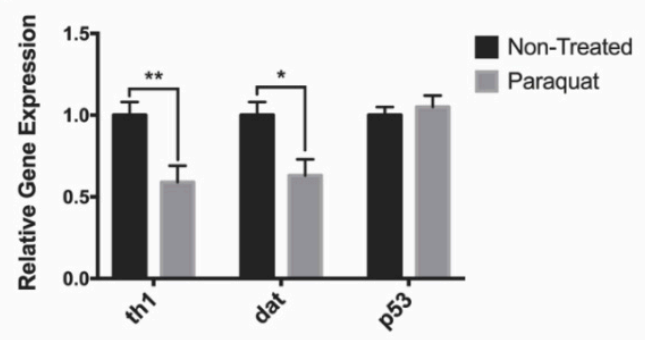

$\mathrm{E}$

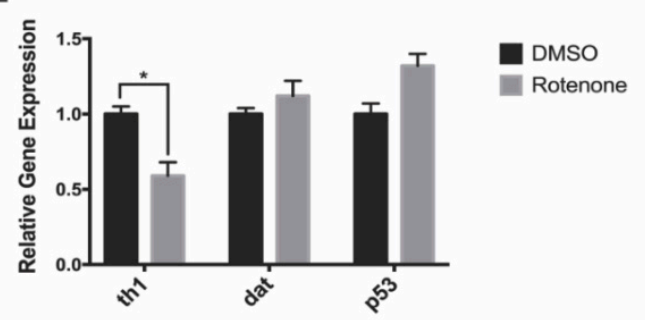

B

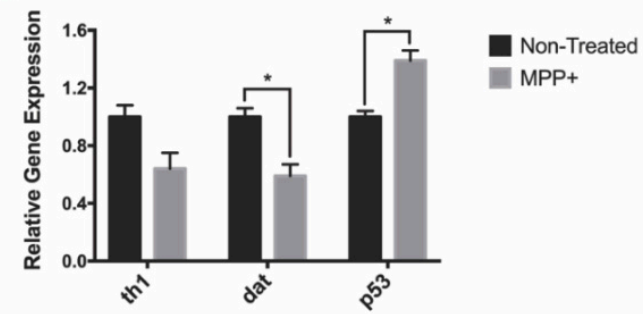

D

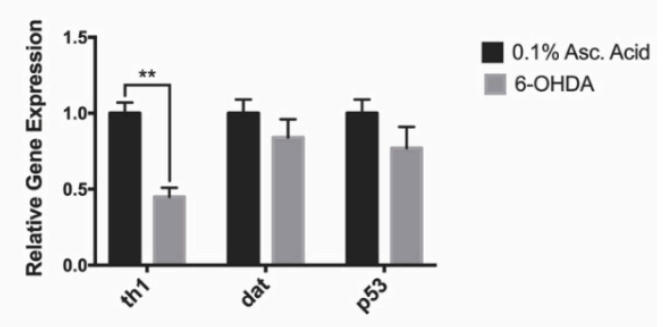

Figure 4. Impact of neurotoxin exposure on dopaminergic- and apoptosis-linked gene expression. (A-E) Relative expression of $d a t$, th1 and $p 53$ of $7 \mathrm{dpf}$ zebrafish following exposure to MPTP, $\mathrm{MPP}^{+}$, paraquat, 6 -OHDA, and rotenone ( $n=3$ pools of 10 larvae). Bars represent the Mean \pm the SEM. $*(p<0.05)$ and ${ }^{* *}(p<0.01)$.

\subsection{Effects on Locomotion}

To further investigate whether the decrease in DAnergic neurons within the vDC affects behavior, we analyzed the zebrafish locomotor activity. The most important reductions in both total distance and velocity were obtained for MPTP-treated larvae ( $80 \%$ and $85 \%$ reductions, respectively, Figure 5A,B). 
A milder impact on locomotion was obtained with the active metabolite $\mathrm{MPP}^{+}$, with only slight $24 \%$ reductions in both total distance and velocity.
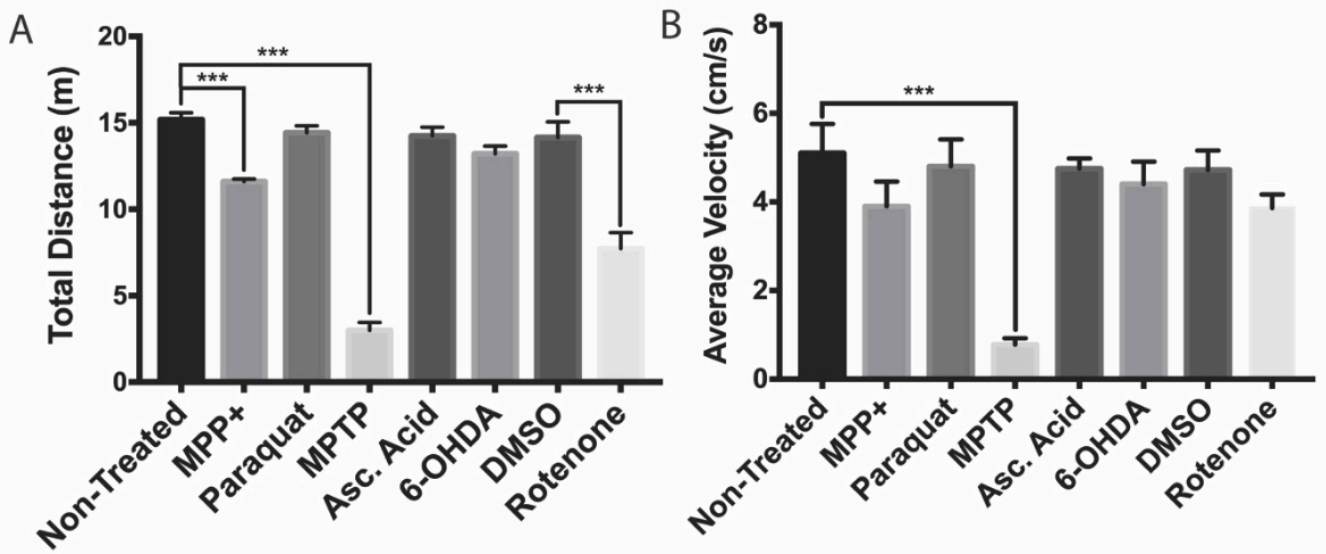

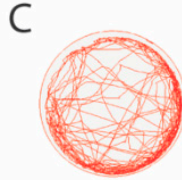

NTC

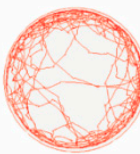

Asc. Acid

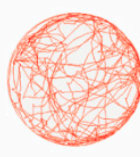

DMSO

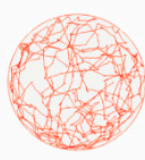

6-OHDA

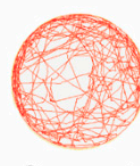

Paraquat

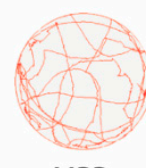

MPP+
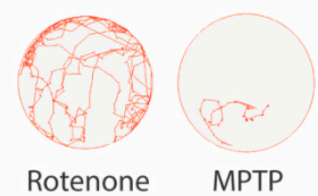

Figure 5. Swimming activity of zebrafish larvae following neurotoxin exposure. All zebrafish were transferred to acclimate to a 6-well plate for 15 mins prior to behavioral analyses. (A,B) Effects of MPTP, $\mathrm{MPP}^{+}$, 6-OHDA, paraquat, and rotenone on total swim distance and average swimming velocity ( $n=20-25$ larvae). (C) Overhead path images of a representative larvae for each exposure group. Bars represent the Mean \pm the SEM. ${ }^{* * *}(p<0.001)$.

Both paraquat and 6-OHDA had no significant impact on locomotion. In contrast, rotenone elicited an effect only on total distance with a $46 \%$ reduction, while the average velocity was unaffected.

\section{Discussion}

With the majority of Parkinsonian pathologies being sporadic, there lies considerable interest in the role of environmental neurotoxin exposure as a contributor of PD. While there have been studies that tested the effects of MPTP, MPP ${ }^{+}$[14], 6-OHDA [43], paraquat, and rotenone [10,38] in larval zebrafish, there have been mixed and contradictory results for each drug. The majority of these studies begin treatment at $24 \mathrm{hpf}$ and continue until $4 \mathrm{dpf}$ or $7 \mathrm{dpf}$ making it difficult to discern whether the observed reductions in DAnergic neurons result from cell death, impairment of DAnergic differentiation, or delayed neurogenesis. In this study, we conducted a direct comparative analysis between MPTP, $\mathrm{MPP}^{+}$, rotenone, 6-OHDA, and paraquat using the same treatment regimen to extrapolate the optimal compound that induces a decrease in DAnergic cells and a locomotor impairing phenotype. In addition, these data will emphasize the neurotoxin-mediated contribution to the onset of PD-related symptoms on zebrafish larvae.

\subsection{MPTP and $M P P^{+}$}

The impact of MPTP on locomotion has been well characterized using in vivo models ranging from rodents [4], to amphibians [44], and medaka [45]. Similarly, in zebrafish, larval exposure to MPTP has been shown to induce DA neurodegeneration within the vDC that translates into a motor phenotype [14]. Following our treatment regimen, starting at $3 \mathrm{dpf}$ to ensure a functional BBB and advanced DAnergic development, our results displayed significant locomotor dysfunction correlating with a 39\% decrease in DAnergic neurons. When contrasting the effects with $\mathrm{MPP}^{+}, \mathrm{MPP}^{+}$treated zebrafish showed a similar degree of DAnergic neuronal ablation, but did not display the same motor 
defects. MPTP requires metabolism MAO-B in the $\mathrm{vDC}$ to exert its neurotoxic effect, as well as the $\mathrm{LC}_{50}$ dose administered being 5 -fold greater than $\mathrm{MPP}^{+}$. However, in zebrafish, the expression of MAO-B within the vDC appears to be low based on spatial distribution, thus limiting MPTP conversion to its active toxic form in this region of the brain [14]. Therefore, the perturbance in motor function shown in the current study may be a result of the constant systemic exposure to a large dose of MPTP. Furthermore, exposure to $0.25 \mathrm{mM}$ of MPTP resulted in the most severe and frequent morphological defects (Figure 2).

Previous studies have shown that $\mathrm{MPP}^{+}$exposure starting at $1 \mathrm{dpf}$ continuing [15] for three days resulted in a decrease in DA neurons only within the diencephalon $[8,14]$. In addition, the decrease in DAnergic neurons was correlated with a decrease in total distance travelled [14], mean velocity and percent of time moving [46]. Our treatment regimen, starting at $3 \mathrm{dpf}$ still resulted in a $36 \%$ loss in the number of DAnergic neurons. Larvae exposed to this concentration of $\mathrm{MPP}^{+}$were observed to be morphologically indistinguishable from controls. Consistent with previous data, the loss of DAnergic neurons was also correlated with a decrease in total distance travelled and mean velocity. However, the decrease in distance traveled and mean velocity observed were modest compared to those obtained with MPTP. This could be due to effects of MPTP secondary metabolites, as also evidenced by the malformations observed that include the development of slight cardiac edemas and upwards tail curvatures (Figure 2).

\subsection{Paraquat}

Although paraquat is structurally similar to $\mathrm{MPP}^{+}$, there remains ambiguity in paraquat's mechanism of action. It is only recently that this mechanism has been linked to genetics where one study identified three candidate genes (POR, ATP7A, and SLC45A4) whose products are required for reactive oxygen species (ROS)-mediated cell death [47]. Paraquat has been shown to cross the BBB in rats to induce dopaminergic toxicity [48], but in the current study paraquat failed to elicit the same degree of DAnergic reductions within the vDC compared to MPTP and $\mathrm{MPP}^{+}$. Paraquat did, however, cause a significant reduction in total eGFP expression in DAnergic cells, as well as a downregulation of th1 and dat transcript levels. Moreover, paraquat had only mild effects, if any, on locomotion. Some reports document a near 3-fold difference in total distance [26], while others did not see the same deficit [10]. Contrarily to Bretaud et al. we found notable morphological defects in zebrafish treated with paraquat alone. We did not observe effects that were specific to any particular organ, but rather a reduction in the overall size of treated larvae (Figure 2).

\subsection{6-OHDA}

Consistent with previous reports [43], zebrafish exposed to $1 \mu \mathrm{M}$ 6-OHDA showed a significant decrease of the number of DAnergic neurons in the vDC. However, this $18 \%$ reduction in DAnergic neurons did not translate into any impairment of locomotor activity. Notably, although relatively scarce, larvae exposed to $1 \mu \mathrm{M}$ were shown to develop severe cardiac malformations. These results contradict those of the study conducted by Feng et al., where they observed moderate and severe motor defects in zebrafish treated with $100 \mu \mathrm{M}$ and $250 \mu \mathrm{M}$ 6-OHDA respectively [43]. This effect may be a consequence of the treatment regimen adopted in that study where larvae were exposed to 6-OHDA once from $24 \mathrm{hpf}$ to $5 \mathrm{dpf}$ prior to the establishment of a functional DAnergic system. Furthermore, despite larval survival at higher concentrations $(3 \mu \mathrm{M}$ and $10 \mu \mathrm{M})$, we found that the effect of these doses on vDC DAnergic numbers to be indistinguishable from those obtained with $1 \mu \mathrm{M}$. Nonetheless, the reduction in $\mathrm{eGFP}^{+}$neurons when contrasted to $\mathrm{MPTP}, \mathrm{MPP}^{+}$, and rotenone may be a consequence of the proposed neuroprotective effects of ascorbic acid $[49,50]$.

\subsection{Rotenone}

Rotenone-induced neurotoxicity has been well documented to contribute to motor deficits in various in vivo models ranging from mice [6], rats [51], and Drosophila [52]. In addition, rotenone 
exposure has been shown to induce Lewy body inclusions and neurodegeneration in mice and rats $[29,53,54]$. However, rotenone exposure in zebrafish has yielded conflicting results. An initial study demonstrated that rotenone exposure of $5 \mu \mathrm{g} / \mathrm{L}$ and $10 \mu / \mathrm{L}$ starting at $24 \mathrm{hpf}$ did not result in a loss of DAnergic neurons or to PD-like locomotor dysfunction [10]. In contrast, another study showed that exposure of larvae for six days starting at $24 \mathrm{hpf}$ resulted in a significant decrease in the number of cells and severe mispatterning within the vDC and the olfactory bulbs [36]. Despite the decrease in DAnergic neurons, there was no major locomotor impairment. Furthermore, morphological defects associated with rotenone exposure in the study of Bretaud et al. only demonstrated a synergistic effect following co-treatment with paraquat. Here, we were able to show that exposure of larval zebrafish to $50 \mathrm{nM}$ rotenone for four days starting at $3 \mathrm{dpf}$ was sufficient to induce a loss of DAnergic neurons within the $\mathrm{VDC}$ and a mild locomotion defect. Moreover, we also observed zebrafish exposed to rotenone developing cardiac malformations (edema; Figure 2, arrowhead). Unexpectedly, we also observed a slight upregulation of $d a t$ following rotenone exposure. This increase may be part of a compensatory mechanism to promote the reuptake of dopamine within surviving neurons.

\subsection{Comparison of Effectiveness between Tested Neurotoxins}

Here we exposed larval zebrafish to respective neurotoxins starting at $3 \mathrm{dpf}$ a time at which the DAnergic system is well established. This allowed us to test the effects of neurotoxic compounds on the survival of DAnergic neurons [55]. Using a consistent immersion treatment regiment, we were able to assess the effectiveness of neurotoxic compounds on inducing DAnergic neuronal loss and locomotor behavior. In line with previously reported studies in mammalian models [5], MPTP exposure resulted in the largest loss of DAnergic neurons. The large loss of DAnergic neurons also coincided with severe locomotion defects such as reduced total distance travelled and average velocity. Meanwhile, MPP elicited a similar degree of DAnergic ablation. However, it only perturbed motor function through total distance travel and not average velocity. Noteworthy between the two neurotoxins, fish exposed to MPTP suffered detrimental cardiac and developmental abnormalities, whereas, fish treated with $\mathrm{MPP}^{+}$were indistinguishable from the non-treated controls suggesting the increased efficiency of $\mathrm{MPP}^{+}$for DAnergic ablation without systemic defects in contrast to MPTP. Like MPP ${ }^{+}$, rotenone was shown to be effective in DAnergic ablation, while only disrupting total distance traveled, although the systemic exposure of rotenone was observed to result in apparent cardiac edemas. The effectiveness of MPTP and rotenone could be attributed to their lipophilic structure allowing for the ease of permeating the BBB $[7,19,20]$. This molecular nature of MPTP and rotenone is beneficial regarding our treatment regimen that uses an immersion approach. This approach relies on BBB diffusion following gill, gut, and skin absorption, and circulatory transport to the brain [15]. Moreover, 6-OHDA uptake is not specific to DAnergic neurons; the use of a norepinephrine transporter inhibitor to block noradrenergic neuron uptake could increase the specificity of neurotoxicity to DAnergic neurons in future zebrafish studies. Paraquat was the least efficient neurotoxic compound to induce DAnergic neuronal loss and locomotor defects in zebrafish. A detailed mode of action of paraquat-induced cell death remains to be defined. However, our result further supports the notion that paraquat alone may not be able to generate substantial oxidative stress to induce cell damage without increasing the exposure to a concentration that will result in significant mortality. Overall, our data suggest that under the current exposure conditions and concentrations, $\mathrm{MPP}^{+}$is the most effective neurotoxin. Being the active metabolite of MPTP, $\mathrm{MPP}^{+}$provides a more direct route to induce substantial DAnergic neuronal loss that translates to a locomotor phenotype without the systemic toxicity observed from MPTP exposure.

\section{Conclusions}

Despite MPTP and rotenone's efficiency in DAnergic ablation and motor perturbation, $\mathrm{MPP}^{+}$ remains as the optimal compound for PD-related recapitulation. Given the ongoing issue of experimental reproducibility, the results of this comprehensive comparison will contribute to alleviate this problem and to shed light onto the extensive neurotoxin contribution to the pathology of PD. 
Following this exposure regimen, using $\mathrm{MPP}^{+}$will provide a most effective and consistent phenotype for Parkinsonian insult that will contribute to the facilitation of therapeutic screening for cellular, motor, and morphological symptoms.

Author Contributions: Conceptualization, M.K., K.H., C.E.D.W. and M.E.; data curation, M.K. and K.H.; formal analysis, M.K. and K.H.; methodology, M.K., K.H. and C.E.D.W.; supervision, M.E.; validation, M.K. and K. H.; visualization, M.K.; writing—original draft, M.K. and K.H.; writing—review and editing, M.K., K.H., S.M.N., C.E.D.W. and M.E. All authors have read and agreed to the published version of the manuscript.

Funding: This research was supported by the Natural Sciences and Engineering Research Council of Canada, grant number 121795.

Acknowledgments: We thank Anwar Norazit for comments on the manuscript and Zaid Karaki for assistance with cell counting.

Conflicts of Interest: The authors declare no conflict of interest. The funders had no role in the design of the study; in the collection, analyses, or interpretation of data; in the writing of the manuscript, or in the decision to publish the results.

\section{Abbreviations}

$\begin{array}{ll}\text { PD } & \text { Parkinson's disease } \\ \text { hpf } & \text { Hour(s) post fertilization } \\ \text { dpf } & \text { Day(s) post fertilization } \\ \text { dpt } & \text { Day(s) post treatment } \\ \text { MPTP } & \text { 1-methyl-4-phenyl-1,2,3,6-tetrahydropyridine } \\ \text { MPP } & \text { 1-methyl-4-phenyl-pyridinium } \\ \text { Paraquat } & \text { Methyl viologen dichloride hydrate } \\ \text { 6-OHDA } & \text { 6-hydroxydopamine } \\ \text { DMSO } & \text { Dimethyl sulfoxide } \\ \text { LC } 50 & \text { Median lethal dose } \\ \text { DAnergic } & \text { Dopaminergic } \\ \text { vDC } & \text { Ventral diencephalon } \\ \text { BBB } & \text { Blood-brain barrier } \\ \text { th } & \text { Tyrosine hydroxylase } \\ \text { dat } & \text { Dopamine transporter } \\ \text { eGFP } & \text { Enhanced green fluorescent protein } \\ \text { SEM } & \text { Standard error of the mean } \\ \text { MAO-B } & \text { Monoamine oxidase B } \\ \text { ETC } & \text { Electron transport chain } \\ \text { mRNA } & \text { Messenger ribonucleic acid } \\ \text { ROS } & \text { Reactive oxygen species } \\ \end{array}$

\section{References}

1. Jankovic, J. Parkinson's disease: Clinical features and diagnosis. J. Neurol. Neurosurg. Psychiatry 2008, 79, 368-376. [CrossRef] [PubMed]

2. Klein, C.; Westenberger, A. Genetics of Parkinson's disease. Cold Spring Harb. Perspect. Med. 2012, 2, a008888. [CrossRef] [PubMed]

3. Dexter, D.T.; Jenner, P. Parkinson disease: From pathology to molecular disease mechanisms. Free Radic. Biol. Med. 2013, 62, 132-144. [CrossRef] [PubMed]

4. Meredith, G.E.; Rademacher, D.J. MPTP mouse models of Parkinson's disease: An update. J. Parkinsons. Dis. 2011, 1, 19-33. [CrossRef]

5. Blesa, J.; Phani, S.; Jackson-Lewis, V.; Przedborski, S. Classic and new animal models of Parkinson's disease. J. Biomed. Biotechnol. 2012, 2012, 845618. [CrossRef]

6. Bhurtel, S.; Katila, N.; Srivastav, S.; Neupane, S.; Choi, D.-Y. Mechanistic comparison between MPTP and rotenone neurotoxicity in mice. Neurotoxicology 2019, 71, 113-121. [CrossRef] 
7. Przedborski, S.; Tieu, K.; Perier, C.; Vila, M. MPTP as a mitochondrial neurotoxic model of Parkinson's disease. J. Bioenerg. Biomembr. 2004, 36, 375-379. [CrossRef]

8. Lam, C.S.; Korzh, V.; Strahle, U. Zebrafish embryos are susceptible to the dopaminergic neurotoxin MPTP. Eur. J. Neurosci. 2005, 21, 1758-1762. [CrossRef]

9. Best, J.D.; Alderton, W.K. Zebrafish: An in vivo model for the study of neurological diseases. Neuropsychiatr. Dis. Treat. 2008, 4, 567-576. [CrossRef]

10. Bretaud, S.; Lee, S.; Guo, S. Sensitivity of zebrafish to environmental toxins implicated in Parkinson's disease. Neurotoxicol. Teratol. 2004, 26, 857-864. [CrossRef]

11. Stewart, A.M.; Braubach, O.; Spitsbergen, J.; Gerlai, R.; Kalueff, A. V Zebrafish models for translational neuroscience research: From tank to bedside. Trends Neurosci. 2014, 37, 264-278. [CrossRef] [PubMed]

12. Du, Y.; Guo, Q.; Shan, M.; Wu, Y.; Huang, S.; Zhao, H.; Hong, H.; Yang, M.; Yang, X.; Ren, L.; et al. Spatial and Temporal Distribution of Dopaminergic Neurons during Development in Zebrafish. Front. Neuroanat. 2016, 10, 115. [CrossRef] [PubMed]

13. Holzschuh, J.; Ryu, S.; Aberger, F.; Driever, W. Dopamine transporter expression distinguishes dopaminergic neurons from other catecholaminergic neurons in the developing zebrafish embryo. Mech. Dev. 2001, 101, 237-243. [CrossRef]

14. Sallinen, V.; Torkko, V.; Sundvik, M.; Reenilä, I.; Khrustalyov, D.; Kaslin, J.; Panula, P. MPTP and MPP+ target specific aminergic cell populations in larval zebrafish. J. Neurochem. 2009, 108, 719-731. [CrossRef] [PubMed]

15. Fleming, A.; Diekmann, H.; Goldsmith, P. Functional characterisation of the maturation of the blood-brain barrier in larval zebrafish. PLoS ONE 2013, 8, e77548. [CrossRef]

16. Sillitoe, R.V.; Vogel, M.W. Desire, Disease, and the Origins of the Dopaminergic System. Schizophr. Bull. 2008, 34, 212-219. [CrossRef]

17. Santana, C.; Rodriguez, M.; Afonso, D.; Arevalo, R. Dopaminergic neuron development in rats: Biochemical study from prenatal life to adulthood. Brain Res. Bull. 1992, 29, 7-13. [CrossRef]

18. Lidow, M.S. D1- and D2 dopaminergic receptors in the developing cerebral cortex of macaque monkey: A film autoradiographic study. Neuroscience 1995, 65, 439-452. [CrossRef]

19. Tieu, K. A guide to neurotoxic animal models of Parkinson's disease. Cold Spring Harb. Perspect. Med. 2011, 1, a009316. [CrossRef]

20. Hare, D.J.; Adlard, P.A.; Doble, P.A.; Finkelstein, D.I. Metallobiology of 1-methyl-4-phenyl-1,2,3, 6-tetrahydropyridine neurotoxicity. Metallomics 2013, 5, 91-109. [CrossRef]

21. Bromilow, R.H. Paraquat and sustainable agriculture. Pest. Manag. Sci. 2004, 60, 340-349. [CrossRef] [PubMed]

22. Richardson, J.R.; Quan, Y.; Sherer, T.B.; Greenamyre, J.T.; Miller, G.W. Paraquat Neurotoxicity is Distinct from that of MPTP and Rotenone. Toxicol. Sci. 2005, 88, 193-201. [CrossRef] [PubMed]

23. Dhillon, A.S.; Tarbutton, G.L.; Levin, J.L.; Plotkin, G.M.; Lowry, L.K.; Nalbone, J.T.; Shepherd, S. Pesticide/Environmental Exposures and Parkinson's Disease in East Texas. J. Agromedicine 2008, 13, 37-48. [CrossRef] [PubMed]

24. Rappold, P.M.; Cui, M.; Chesser, A.S.; Tibbett, J.; Grima, J.C.; Duan, L.; Sen, N.; Javitch, J.A.; Tieu, K. Paraquat neurotoxicity is mediated by the dopamine transporter and organic cation transporter-3. Proc. Natl. Acad. Sci. USA 2011, 108, 20766-20771. [CrossRef]

25. Wang, X.; Souders, C., II; Zhao, Y.; Martyniuk, C. Exposure to paraquat affects mitochondrial bioenergetics, dopamine system expression, and locomotor activity in zebrafish (Danio rerio). Chemosphere 2017, 191, $106-117$. [CrossRef]

26. Nellore, J.; P, N. Paraquat exposure induces behavioral deficits in larval zebrafish during the window of dopamine neurogenesis. Toxicol. Reports 2015, 2, 950-956. [CrossRef]

27. Bortolotto, J.; Cognato, G.; Rilo Christoff, R.; Nery, L.; Leite, C.; Kist, L.; Bogo, M.; Vianna, M.; Bonan, C. Long-Term Exposure to Paraquat Alters Behavioral Parameters and Dopamine Levels in Adult Zebrafish (Danio Rerio). Zebrafish 2014, 11, 142-153. [CrossRef]

28. Reader, T.; Dewar, K.M. Review article Effects of denervation and hyperinnervation on dopamine and serotonin systems in the rat neostriatum: Implications for human Parkinsons disease. Neurochem. Int. 1999, 34, 1-21. [CrossRef]

29. Dauer, W.; Przedborski, S. Parkinson's Disease: Mechanisms and Models. Neuron 2003, 39, 889-909. [CrossRef] 
30. Bové, J.; Perier, C. Neurotoxin-based models of Parkinson's disease. Neuroscience 2012, 211, 51-76. [CrossRef]

31. Fulceri, F.; Biagioni, F.; Lenzi, P.; Falleni, A.; Gesi, M.; Ruggieri, S.; Fornai, F. Nigrostriatal Damage with 6-OHDA. Ann. N. Y. Acad. Sci. 2006, 1074, 344-348. [CrossRef] [PubMed]

32. Nanda, N.B.P.; Das, P.C.; Jena, J. Use of Rotenone as Piscicide: Toxicity Levels in a Few Common Freshwater Predatory and Weed Fishes. J. Appl. Aquac. 2009, 21, 241-249. [CrossRef]

33. Ott, K.C.; Rotenone, D.P. A Brief Review of its Chemistry, Environmental Fate, and the Toxicity of Rotenone Formulations. Available online: https://pdfs.semanticscholar.org/2944/ 9a8fda74b7bb956f78aca6169b14b44bdb14.pdf (accessed on 23 April 2006).

34. Cabezas, R.; Fidel, M.; Torrente, D.; Santos El-Bach, R.; Morales, L.; Gonzalez, J.; Barreto, G.E. Astrocytes Role in Parkinson: A Double-Edged Sword. In Neurodegenerative Diseases; IntechOpen: London, UK, 2013.

35. Sinha, P.; Ghosh, N.; Mitra, S.; Bhattacharyya, A. Neuroinflammation during Parkinson's Disease: Key Cells and Molecules Involved in It. Inflamm. Common Link Brain Pathol. 2016, 185-208.

36. Martel, S.; Keow, J.Y.; Ekker, M. Rotenone Neurotoxicity Causes Dopamine Neuron Loss in Zebrafish. Univ. Ottawa J. Med. 2015, 5, 16-21. [CrossRef]

37. Xi, Y.; Yu, M.; Godoy, R.; Hatch, G.; Poitras, L.; Ekker, M. Transgenic zebrafish expressing green fluorescent protein in dopaminergic neurons of the ventral diencephalon. Dev. Dyn. 2011, 240, 2539-2547. [CrossRef]

38. Keow, J. Physiological and Behavioral Changes in a Rotenone Model of Dopamine Neurotoxicity and Neurodegeneration in Zebrafish. Ph.D Thesis, University of Ottawa, Ottawa, ON, Canada, 2016.

39. Barreto-Valer, K.; López-Bellido, R.; Macho Sánchez-Simón, F.; Rodríguez, R.E. Modulation by Cocaine of Dopamine Receptors through miRNA-133b in Zebrafish Embryos. PLoS ONE 2012, 7, e52701. [CrossRef]

40. Chen, Y.-C.; Semenova, S.; Rozov, S.; Sundvik, M.; Bonkowsky, J.L.; Panula, P. A Novel Developmental Role for Dopaminergic Signaling to Specify Hypothalamic Neurotransmitter Identity. J. Biol. Chem. 2016, 291, 21880-21892. [CrossRef]

41. Tang, R.; Dodd, A.; Lai, D.; McNabb, W.C.; Love, D.R. Validation of Zebrafish (Danio rerio) Reference Genes for Quantitative Real-time RT-PCR Normalization. Acta Biochim. Biophys. Sin. 2007, 39, 384-390. [CrossRef]

42. Vaz, R.L.; Outeiro, T.F.; Ferreira, J.J. Zebrafish as an Animal Model for Drug Discovery in Parkinson's Disease and Other Movement Disorders: A Systematic Review. Front. Neurol. 2018, 9, 347. [CrossRef]

43. Feng, C.; Chen, C. Effects of 6-Hydroxydopamine Exposure on Motor Activity and Biochemical Expression in Zebrafish (Danio Rerio) Larvae. Zebrafish 2014, 11, 227-239. [CrossRef]

44. Barbeau, A.; Dallaire, L.; Buu, N.T.; Poirier, J.; Rucinska, E. Comparative behavioral, biochemical and pigmentary effects of MPTP, MPP+ and paraquat in rana pipiens. Life Sci. 1985, 37, 1529-1538. [CrossRef]

45. Matsui, H.; Taniguchi, Y.; Inoue, H.; Uemura, K.; Takeda, S.; Takahashi, R. A chemical neurotoxin, MPTP induces Parkinson's disease like phenotype, movement disorders and persistent loss of dopamine neurons in medaka fish. Neurosci. Res. 2009, 65, 263-271. [CrossRef] [PubMed]

46. Farrell, T.C.; Cario, C.L.; Milanese, C.; Vogt, A.; Jeong, J.-H.; Burton, E.A. Evaluation of spontaneous propulsive movement as a screening tool to detect rescue of Parkinsonism phenotypes in zebrafish models. Neurobiol. Dis. 2011, 44, 9-18. [CrossRef] [PubMed]

47. Reczek, C.R.; Birsoy, K.; Kong, H.; Martínez-Reyes, I.; Wang, T.; Gao, P.; Sabatini, D.M.; Chandel, N.S. A CRISPR screen identifies a pathway required for paraquat-induced cell death. Nat. Chem. Biol. 2017, 13, 1274. [CrossRef] [PubMed]

48. Shimizu, K.; Ohtaki, K.; Matsubara, K.; Aoyama, K.; Uezono, T.; Saito, O.; Suno, M.; Ogawa, K.; Hayase, N.; Kimura, K.; et al. Carrier-mediated processes in blood-brain barrier penetration and neural uptake of paraquat. Brain Res. 2001, 906, 135-142. [CrossRef]

49. Casarejos, M.J.; Canals, S.; De Bernardo, S.; Mena, M.A.; Rodrı, E. Thiolic antioxidants protect from nitric oxide-induced toxicity in fetal midbrain cultures. Neuropharmacology 2002, 43, 877-888.

50. Riederer, P.; Sofic, E.; Rausch, W.; Schmidt, B.; Reynolds, G.P.; Jellinger, K.; Youdim, M.B.H. Transition Metals, Ferritin, Glutathione, and Ascorbic Acid in Parkinsonian Brains. J. Neurochem. 1989, 52, 515-520. [CrossRef]

51. Swarnkar, S.; Singh, S.; Mathur, R.; Patro, I.; Nath, C. A study to correlate rotenone induced biochemical changes and cerebral damage in brain areas with neuromuscular coordination in rats. Toxicology 2010, 272, 17-22. [CrossRef]

52. Coulom, H.; Birman, S. Chronic exposure to rotenone models sporadic Parkinson's disease in Drosophila melanogaster. J. Neurosci. 2004, 24, 10993-10998. [CrossRef] 
53. Betarbet, R.; Sherer, T.B.; MacKenzie, G.; Garcia-Osuna, M.; Panov, A.V.; Greenamyre, J.T. Chronic systemic pesticide exposure reproduces features of Parkinson's disease. Nat. Neurosci. 2000, 3, 1301-1306. [CrossRef]

54. Liu, Y.; Sun, J.-D.; Song, L.-K.; Li, J.; Chu, S.-F.; Yuan, Y.-H.; Chen, N.-H. Environment-contact administration of rotenone: A new rodent model of Parkinson's disease. Behav. Brain Res. 2015, 294, 149-161. [CrossRef] [PubMed]

55. Kastenhuber, E.; Kratochwil, C.F.; Ryu, S.; Schweitzer, J.; Driever, W. Genetic dissection of dopaminergic and noradrenergic contributions to catecholaminergic tracts in early larval zebrafish. J. Comp. Neurol. 2010, 518, 439-458. [CrossRef] [PubMed]

(C) 2019 by the authors. Licensee MDPI, Basel, Switzerland. This article is an open access article distributed under the terms and conditions of the Creative Commons Attribution (CC BY) license (http://creativecommons.org/licenses/by/4.0/). 